\title{
A invisibilidade do desemprego juvenil no discurso mediático da imprensa portuguesa
}

\author{
Bruno Carriço Reis*, João Carlos Sousa**
}

* Professor Auxiliar na Universidade Autónoma de Lisboa, Portugal / Investigador do Núcleo de Estudos em Arte, Media e Política (PUC-SP), Brasil (reysbr@ual.pt)

** licenciado e mestre em sociologia pela Universidade da Beira Interior. Desenvolveu investigação no Labom-UBI (2010-2015). Actualmente é investigador do Obercom, Lisboa, Portugal (joaoclsousa@gmail.com)

Resumo

\begin{abstract}
A actual crise internacional, que deriva do colapso subprime de 2007, gerou um efeito económico recessivo à escala global. No contexto português uma das consequências maiores do fenómeno é o acentuar da precarização laboral e o aumento do desemprego juvenil. Importa perceber como a imprensa diária constrói a cobertura mediática deste fenómeno social e em que termos propõe o debate público. Para a concretização do objectivo enunciado efectuámos em dois jornais diários portugueses uma análise de conteúdo, apurando frequências e temáticas discursivas acerca do desemprego juvenil. Os resultados revelam um alheamento mediático em relação ao fenómeno, que prima por uma cobertura minimalista e um excessivo enfoque institucional do problema, prática que neutraliza a compreensão da complexidade do fenómeno.
\end{abstract}

Palavras-chave: desemprego juvenil, crise, representações mediáticas.

Abstract

The present international crisis, rooted in the 2007 subprime lending crisis, had a major economic impact at a global scale. For Portugal, main consequences included the increase of insecure jobs and the rise of youth unemployment. From the perspective of media studies, it was important to understand how the media covered both the phenomena and in what ways public debate around insecure jobs and youth unemployment was promoted. The methodology adopted was built-in the content analysis of two Portuguese daily newspapers, namely frequency and textual analysis. Results evidence the detachment of media in relation to the phenomena. Alternatively, media opted for a minimalist coverage characterized by an excessive institutional focus of the problem, thus avoiding a full comprehension of the complexity of the phenomena.

Keywords: youth unemployment, crisis, media representations.

\section{Nota de abertura: a problemática do desemprego juvenil}

Desde o início deste século, que podemos constatar que a questão do desemprego povoa recorrentemente as inquietações dos portugueses, basta para o efeito verificar o lugar cimeiro que esta temática ocupa nas sondagens de opinião que periodicamente se realizam ${ }^{1}$. Tal manifestação da opinião pública parece andar alinhada com a taxa de desemprego, que segundo os dados do Instituto Nacional de Estatística (INE), tem

\footnotetext{
${ }^{1}$ No ano de 2003, num estudo de opinião realizado pela empresa Novadir, $47,9 \%$ dos inquiridos considerava que a questão do emprego/desemprego era o assunto que mais os preocupava. No ano de 2016, a Multidados, concluiu que $28 \%$ dos inquiridos tinham como principal preocupação a situação económica e financeira, e a questão do desemprego apareceria em segundo lugar com $26 \%$.
}

Copyright @ 2017 (Bruno Carriço Reis, João Carlos Sousa). Licensed under the Creative Commons Attribution-NonCommercial Generic (cc by-nc). Available at http://obs.obercom.pt. 
crescido de forma acentuada desde o advento do milénio. A realidade laboral portuguesa passou de um cenário de pleno emprego (3,9\% de desempregados em 2000) para actuais taxas de desemprego superiores a dois dígitos (atingindo o seu máximo em 2013 com 16,2\%).

Mas o fenómeno do desemprego não se regista como uma especificidade da economia portuguesa. Esta é uma tendência generalizada das sociedades pós-industriais (Bell, 1999), assentes em novas formas de organização de trabalho e de negócio. Emerge dai uma renovada racionalidade capitalista que assenta num sistema intensamente comunicado e tecnológico, com uma elevada interdependência entre as nações, que desemboca num processo de economia-mundo. Portugal, estruturalmente um país economicamente débil, com baixa produtividade e uma dependência significativa do exterior (Amaral, 2010), fica exposto as contingências de um modelo capitalista de enorme flexibilidade (Sennett, 1998).

"O desemprego em Portugal tem inúmeras causas, nomeadamente a concorrência de países produtores de bens a baixo custo, com os quais Portugal não consegue competir, bem como a introdução de novas tecnologias que contribui para a eliminação de muitos postos de trabalho. A atual crise económica pela qual a economia portuguesa está a passar também é apontada como uma causa do aumento do desemprego, afetando vários setores de atividade" (Sá, 2014: 36).

A crise a que se refere o autor, ficou conhecida como crise do subprime, despoletou em 2007 e afectou a economia-mundo. Um colapso financeiro bolsista ocorrido nos Estados Unidos que provocou em forma de cascata, danos profundos e generalizados no sistema capitalista. A economia portuguesa acabou por não resistir ao embate e o governo português acabou por pedir ajuda externa no ano de 2011. A crise veio agravar o já débil crescimento económico português, gerando uma deterioração do mercado de trabalho, que se traduziu num crescente aumento no número de desempregados (Ribeiro, Frade, Coelho e Ferreira-Valente, 2015). Em particular e de forma muito expressiva junto dos jovens² (Matos, Domingos e Kumar, 2011; Pereira, 2013), que em situação de recessão económica experimentam uma dificuldade crescente no acesso ao mercado laboral (Gonçalves, 2005), sendo que "a taxa de desemprego jovem é quase o dobro da taxa de desemprego total" (INE, 2014: 1).

Mas como assinalam Berlingieri, Bonin e Sprietsma (2014: 3) "o desemprego jovem não é um fenómeno recente, que possa ser atribuído apenas à última forte recessão económica. Há muitos anos que a maioria dos países europeus tem dificuldades em integrar os jovens no mercado de trabalho. O desemprego entre os jovens é, em geral, significativamente maior do que entre os adultos".

A natureza estrutural do fenómeno consubstancia-se na enorme dificuldade de iniciarem um trajecto profissional (Lopes, 2013), pese serem gerações, manifestamente mais escolarizadas e qualificadas que as anteriores ${ }^{3}$ (INE, 2014). É notória a subida do desemprego entre os jovens dotados de credenciais escolares de nível superior. Este acréscimo, poderá em parte ser explicado por estratégias de resistência a empregos precários ou desqualificados, fazendo uso do apoio familiar por parte destes jovens diplomados, que apostam e investem na educação com expectativas partilhadas de ascensão (ou reprodução) social - "desemprego juvenil de prospecção" como apelida Vieira (2006:110). Mas a complexidade do fenómeno traduz outros dois comportamentos juvenis típicos perante

\footnotetext{
${ }^{2}$ Consideramos jovens, todos aqueles indivíduos cuja idade está compreendida entre os 15 e os 29 anos, em sintonia com a categorização usada pelo INE.

${ }^{3}$ Verificar tendência em: http://www.pordata.pt/Portugal/Populacao+residente+com+15+a+64+anos+e+65+e+mais+anos+por+nivel+de+escolaridad e+completo+mais+elevado-332
} 
as dificuldades laborais. Por um lado, "agarram-se a quaisquer possibilidades de inserção" (Wickert, 2006: 269), sujeitando-se a condições que Ihes são impostas. Por outro lado, o descompasso existente entre formação e inserção do mercado de trabalho tem contribuído para um gorar das expectativas juvenis, que perante as dificuldades de entrarem no mercado de trabalho abdicam, tanto de estudar, como de procurarem ocupações profissionais. Os sociológicos caracterizaram estes jovens como estando numa situação NEEF, fenómeno que regista em Portugal uma incidência de $14 \%$ entre os indivíduos com uma idade compreendida entre os 15 e os 24 anos (Rowland, Ferreira, Vieira e Pappámikail (2014).

Constatamos de igual forma, na literatura que se debruça sobre o assunto, abordagens que vincam uma crescente precarização das condições de trabalho dos jovens (Oliveira e Carvalho, 2010), maioritariamente em situação de desprotecção laboral (Vilas, 2013) e desigualdade em relação a outros trabalhadores que desempenham funções similares, já que "os jovens dos 15 aos 29 anos têm rendimentos do trabalho inferiores à média nacional e essa diferença tem aumentado" (INE, 2014: 1). Como salientam Alves, Poças e Tomé (2013), tal sucede, pois os mecanismos de protecção laboral, mesmo os de natureza corporativa, estão mais focados nos trabalhadores permanentes que nos jovens precarizados.

Perante um cenário adverso, a transição para a idade adulta fica substancialmente comprometida, "estas dificuldades condicionam e adiam a decisão dos jovens em constituir família e sair de casa dos pais" (INE, 2014: 1). A precarização da vida destes jovens não obedece somente a uma dimensão de natureza económica, conforma-se na multidimensionalidade afectiva, anímica, existencial (Alves, Cantante, Baptista e Carmo, 2011). Pese a que nem todos os jovens reagem de igual forma perante a adversidade (País, 1991 e 2003), é preciso fazer notar, que uma situação de desemprego prolongado nos primórdios da vida activa, ou de uma manifesta precarização laboral, parece contribuir fortemente para que se registem efeitos traumáticos nos jovens (Hughes e Borbély-Pecze, 2014). Atendendo pois à centralidade que a questão do emprego/desemprego ocupa na sociedade portuguesa, faz para nós todo o sentido perceber em que moldes se propõe o debate público acerca do tema. Estamos particularmente interessados em perceber, que enquadramento jornalístico se oferece para a problemática do desemprego juvenil, fenómeno que se intensificou de forma severa com o eclodir da crise subprime e com a posterior entrada em 2011 da troika em Portugal.

\section{Proposta de estudo da cobertura da imprensa em relação ao desemprego juvenil}

O presente texto tem como finalidade compreender os enunciados jornalísticos produzidos acerca do desemprego juvenil em dois diários portugueses; no Correio da Manhã (CM), por ser actualmente o impresso com maior tiragem diária, e no jornal Público, que se caracteriza por ser um título de referência no espaço mediático português. Estes dois títulos apresentam uma assinalável penetração no quotidiano dos portugueses. Atendendo aos dados disponíveis (Marktest, 2012), o Correio da Manhã liderou os generalistas com 14.2\% de audiência anual média e o jornal Público com 5.1\% veio em terceiro lugar, depois do Jornal de Notícias com 11.4\%. A nossa escolha recaiu nos dois primeiros, descartamos o Jornal de Notícias por ser um título com um pendor "regionalista" nortenho.

Ao optarmos pelo Público e pelo Correio da Manhã procurou-se garantir um efeito contrastante na cobertura mediática, contemplando jornalismo de referência (Público) e jornalismo popular (Correio da Manhã). Atendemos a esta caracterização, tomando como critério trabalhos anteriores, que estudaram as identidades jornalísticas dos periódicos em questão. No Correio da Manhã foi observada uma cobertura mediática assente numa lógica de dramatização, onde prima um tom de espectacularização, construído com recurso a uma abordagem de teor 
escandaloso (Fragoso, 2010; Lima e Reis, 2014). No caso do jornal Público, Cardoso (2007: 244) discute de forma detalhada os critérios para se categorizar o periódico na denominada imprensa de referência. $O$ argumento de fundo, para se atender a esta classificação, recai numa prática jornalística reconhecida como modelar e orientadora do debate público, "produzindo um efeito de arrasto" para os restantes meios de comunicação (Reig, 1998: 154).

O critério de escolha tentou contemplar propostas jornalísticas que representam modelos mediáticos divergentes, o intuito é o de percebermos como respondem em termos de agendamento e cobertura temática as aproximações mais populares do Correio da Manhã e em que moldes se estabelece a cobertura de referência que caracteriza o Público. Daqui resulta uma questão central; O tratamento mediático do desemprego juvenil recebe atenção jornalística diferenciada dependendo das publicações? Tentamos assim analisar em que medida os jornais, como meios de comunicação de características mais reflexivas, abordam a temática do (des)emprego e Ihe conferem dimensão explicativa, já que o desemprego se converteu em assunto prioritário da agenda política4. No contexto português, o despoletar da crise subprime intensificou uma crescente espiral recessiva. Os efeitos sociais que derivam da retracção económica assumem uma relevância empírica maior a partir de 2009, com a crescente destruição do tecido produtivo ${ }^{5}$ e o consequente aumento do desemprego e em particular na sua variante jovem 6 . Atendendo a este facto, o nosso corpus analítico teve inicio a Janeiro de 2009 até ao mês de Dezembro de 2013. Para o efeito procedemos à identificação nas edições em formato papel dos jornais Público e Correio da Manhã, das chamadas de capa que fizessem referência ao tema do desemprego. Utilizámos este atalho de selecção levando em linha de conta a transversalidade da temática na vida pública nacional, o que suporia tratamento prioritário na cobertura informativa. Para o efeito, determinámos todo um léxico associado que permitiria ampliar a complexa dimensão da questão social em análise. Assim, a seleç̧ão das peças analisadas foi realizada a partir dos termos "desemprego juvenil", complementada pela família de palavras que aludem de forma directa ao imaginário semântico em escrutínio, como sejam; "despedimento", "falência", "rescisão" "subsídio desemprego", "centro de emprego", "precariedade", "crise", etc.

Uma vez identificado o desemprego juvenil como estandarte de primeira página, codificámos as peças que no interior dos jornais lhe faziam referência. Registámos a respectiva seç̧ão onde esta se encontrava e o género informativo noticioso que the correspondia (notícia/breve/entrevista/reportagem). Seguidamente, aferíamos se as informações possuíam ou não enquadramento visual e quem eram os actores presentes no discurso mediático (Jovens/Instituição/Outros). Para complementarmos a recolha de dados, procedemos posteriormente à categorização temática das notícias, construindo etiquetas capazes de agrupar as similitudes da cobertura jornalística das duas publicações em análise. Este procedimento teve como intuito facilitar-nos a tarefa interpretativa, no sentido de melhor descodificarmos as tendências dos respectivos jornais no enunciar do tema do desemprego e em concreto do enfoque posto na abordagem juvenil do desemprego.

Propomos então uma dupla leitura mediática do desemprego. Numa primeira parte incidiremos na sua formulação mais abrangente e posteriormente, num segundo momento, na sua especificidade juvenil.

\footnotetext{
${ }^{4}$ Leia-se para o efeito o relatório de 2014 do Eurofound que como eixo central aborda o agravamento da situação laboral dos jovens no contexto de crise: http://www.eurofound.europa.eu/sites/default/files/ef files/pubdocs/2013/92/en/1/EF1392EN.pdf 5 Ver para o efeito o estudo elaborado pela COSEC acerca das insolvências: http://www.aip.pt/irj/go/km/docs/sitemanager/www aip pt/documentos/homepage/informacao/201302 COSECInsolvencias $12 \% 20 \% 284 \% 29$.pdf

${ }^{6} \mathrm{O}$ crescimento das taxas de desemprego eclodiu de forma transversal num crescente número de países ocidentais. Segundo os dados do Pordata, numa década, a Europa dos 27 passou de uma taxa média de desemprego em 2002 de 8,9\% para 10,4\% em 2012. Comparativamente, no caso português, o desemprego atingiu uma maior severidade, passamos de uma taxa de 7,6\% de desempregados em 2008 para uma taxa de 9,4\% em 20096. Em 2013 o desemprego atingiria um marco histórico, $16,4 \%$ da população activa portuguesa estava oficialmente sem emprego.
} 


\section{Resultados iniciais; o tratamento jornalístico do desemprego}

Procedemos neste apartado ao tratamento dos dados obtidos na recolha empírica, em que cada tabela apresentada e analisada expressa a categorização por nós efectuada. Mas antes de nos adentrarmos na descodificação do conteúdo jornalístico, comecemos por comparar a preponderância da questão do desemprego, de 2009 a 2013, em cada um dos periódicos escrutinados.

Figura 1 - Total de notícias que versam acerca da questão do desemprego nos jornais Público e Correio da Manhã (2009-2013)

\begin{tabular}{lll}
\hline \hline & Frequência & $\%$ \\
\hline Público & 156 & 80,4 \\
Correio da Manhã & 38 & 19,6 \\
Total & 194 & 100,0 \\
\hline \hline
\end{tabular}

Fonte: Elaboração Própria

Um ponto que importa frisar, é que comparando a cobertura dada por cada um dos diários, verificamos uma gritante desproporcionalidade no número de peças colectadas em cada um deles. Enquanto no Público recolhemos 156 unidades (o que traduz um 80.4\% do total de informações recolhidas), no Correio da Manhã obtivemos 38 unidades, do total de 194 unidades analisadas. O manifesto desequilíbrio entre as duas publicações parece poder ser explicado por modelos de produção jornalística diferenciados. A agenda e o discurso são editorializados no sentido de responderem a um dado critério jornalístico, reconhecido pelos leitores das publicações.

Comecemos pelo Correio da Manhã, em que o critério de noticiabilidade tem como matriz uma cobertura emocional com uma forte dramatização do acontecimento reportado (Agee e Traquina, 1984). Uma abordagem que privilegia um enquadramento servido de soft news, informações relacionadas com as "debilidades humanas" (Tuchman, 1978) e leituras jornalísticas simplificadas em relação aos fenómenos sociais em análise. Este enfoque jornalístico parece atender ao perfil do leitor do Correio da Manhã; com escolarização ao nível do ensino básico/secundário e pertencente a classe média/média baixa (OBERCOM, 2006; Marktest, 2016).

O tema do desemprego parece não ter as "qualidades intrínsecas", enunciadas acima, para ser alvo de tratamento informativo privilegiado. As próprias temáticas propõem um determinado jornalismo e um modo de vínculo com os leitores, o que Schlesinger (1978) apelidou de "quadro de expectativas estáveis". O desemprego não se estabelece como abordagem prioritária do jornal, factor que condiciona fortemente a chamada à primeira página, pois existe uma hierarquização da realidade a retratar. De forma complementar ao trabalho enunciado constatamos uma tendência no enquadramento tipo das chamadas de manchete, que pela regularidade detectada7 pressupõem uma clara orientação editorial que assenta em quatro elementos tipificadores:

a) Um discurso fortemente hostil para com a classe política e governativa, com um pendor de escrutínio denunciador que se apresenta ideologicamente transversal para com os agentes políticos, visando sublinhar o sentido de independência da publicação em relação às esferas de poder. 0 tom assertivo utilizado propõe um discurso de contundente autoridade moral, que intensifica claramente 0 aparato discursivo do senso comum, penalizando o exercício dos agentes políticos independentemente do quadrante que estes representam;

\footnotetext{
7 Pese a recorrência dos 4 enunciadores tipo em toda a temporalidade analisada, utilizamos de forma ilustrativa títulos de um ano em concreto (2012), por permitir uma coerência contextual maior dentro da unidade de amostra.
} 
"Paulo Campos ganhou 8 mil por mês. Rendimento médio dos últimos onze anos" (CM, 22/10/2012)

"Relvas tem reforma de 2880 euros por mês. Subvenção vitalícia por 12 anos de actividade política" $(\mathrm{CM}, 14 / 07 / 2012)$

"Sócrates gasta 15000 por mês" (CM, 16/03/2012)

"Políticos ganham mais 81 euros por mês. Revelamos dados oficiais das finanças (CM, 28/08/2012)

b) Uma cobertura mediática justicialista, que tem como pedra de toque as marcadas assimetrias sociais existentes no país. Os enunciados propõem a discussão de um "sentido da ordem" social (Gans, 1979), que assumindo os desequilíbrios decorrentes da estratificação propõe um empoderamento do público indefeso;

"Fisco lança 'caça à bomba'. PSP e GNR dão mão a máquina dos impostos" (CM, 06/06/2012)

"Patrões defendem fim de subsídios. $13^{\circ}$ e $14^{\circ}$ mês pagos em duodécimos" (CM, 29/12/2012)

"Patrões ricos lucram 100 milhões. Grandes empresas ganham com austeridade através da baixa da TSU" (CM, $11 / 09 / 2012)$

"Patrões ganham 4,5 mil milhões com novas leis. Cavaco promulga código laboral" (CM, 19/06/2012)

c) Uma cobertura jornalística paternalista que reforça os valores dominantes, consensuais e estendidos da sociedade portuguesa, como sejam a defesa intransigente da família e do funcionalismo público. 0 compromisso gerado reforça laços de solidariedade (capitalizados em fidelização de leitura/consumo) e de sintonia social, o jornal funciona como porta-voz dos anseios dos leitores/consumidores;

"Novos cortes na função pública. Salários e pensões penalizados" (CM, 09/10/2012)

"Novos cortes nas reformas e função pública. Mais 300 mil penalizados. Rendimentos entre 600 e 1350 brutos castigados" (CM, 30/11/2012).

"Função pública e reformados perdem 10 mil euros" (CM, 01/05/2012)

"Passos tira 8500 euros a cada funcionário público" (CM, 07/04/2012)

"Ter filhos custa 10 mil por ano, contas INE. Famílias com crianças gastam mais 31 por cento" (CM, 21/06/2012)

"Corte de 154 milhões nos benefícios de filhos e deficientes" (CM, 29/08/2012).

d) O recurso à espectacularização do "mundo da vida", onde a violência e o macabro, desvelam a realidade que se constitui para além das agendas formais da vida pública. A dramatização do quotidiano reforça a função social do jornal, que revela e expõe a vida em todo o seu esplendor;

"GNR sem dinheiro reduz policiamento" (CM, 16/11/2012)

"Assaltos a casas disparam 330\%. Crime sobe na zona de Lisboa" (CM, 05/06/2012)

"Disparam casos de bebes abandonados. Sobem de 12 para 25 no Amadora-Sintra" (CM, 20/11/2012). 
Podemos constatar que a primeira página do jornal assenta numa modelização, que se poderia resumir em três tópicos; 1) O acentuar do valor da notícia por via de um processo de personalização, que estabelece níveis de empatia maior com o leitor, comparativamente com os mecanismos explicativos da generalização. 2) Decorrente do ponto anterior, os actores sociais são representados desde a sua dimensão privada, sempre justificada por um necessário interesse público; seja no escrutínio da vida dos famosos, na avaliação de desempenho dos políticos (sublinhado nomes e apelidos) ou na forma ostensiva como estigmatizam prevaricadores. 3) Por fim, constatamos um enfoque jornalístico que assume um papel reparador de uma realidade entendida como desestruturada (Galtung e Ruge, 1981). O jornalismo é elevado a uma dimensão moral, construindo quadros de referência para o seu público.

Todas as características evidenciadas, são alimentadas por uma forte componente visual, que responde a uma necessidade de exposição declarada e emotiva. Basta para o efeito registar que todas as peças analisadas no Correio da Manhã acerca do desemprego eram acompanhadas de fotografias. O elemento visual operava invariavelmente como moldura de atalho para o discurso informativo, operando como recurso emocional que tentava sublinhar o aspecto central mais dramático a reter da peça. Metade dessas peças possuíam informação infográfica (gráficos e quadros), com o objectivo notório de produzirem um efeito de resumo com dados categóricos para o "convencimento" dos públicos.

Se procedermos a estabelecer comparativamente a utilização do acompanhamento visual por parte do Público, percebemos uma diluição da utilização fotográfica como necessidade ilustrativa $(63,5 \%$ das peças tinham fotografia) e do recurso a infografia com menor regularidade (em um terço das peças). Os recursos eram utilizados desde um prisma de apresentação de dados de forma mais aberta, para potenciarem uma reflexão dialógica com a informação do próprio texto jornalístico.

o que concerne ao tratamento da temática por parte do jornal Público, pese o tema do desemprego ter um enfoque de carácter limitado, opera num quadro de referências mais lato, em particular no tocante às temáticas abordadas. A explicação para uma maior expansão da cobertura está na própria génese do jornalismo de referência que representa o periódico. Não será alheio a este facto o perfil dos seus leitores; tendencialmente escolarizados ao nível do ensino universitário (OBERCOM, 2006; Marktest, 2016). Um jornalismo mais reflexivo dita um conjunto maior de ângulos e perspectivas de entendimento da temática em análise, como elucida a Tabela 2.

Figura 2 - Categorização temática das peças acerca de desemprego nos dois jornais

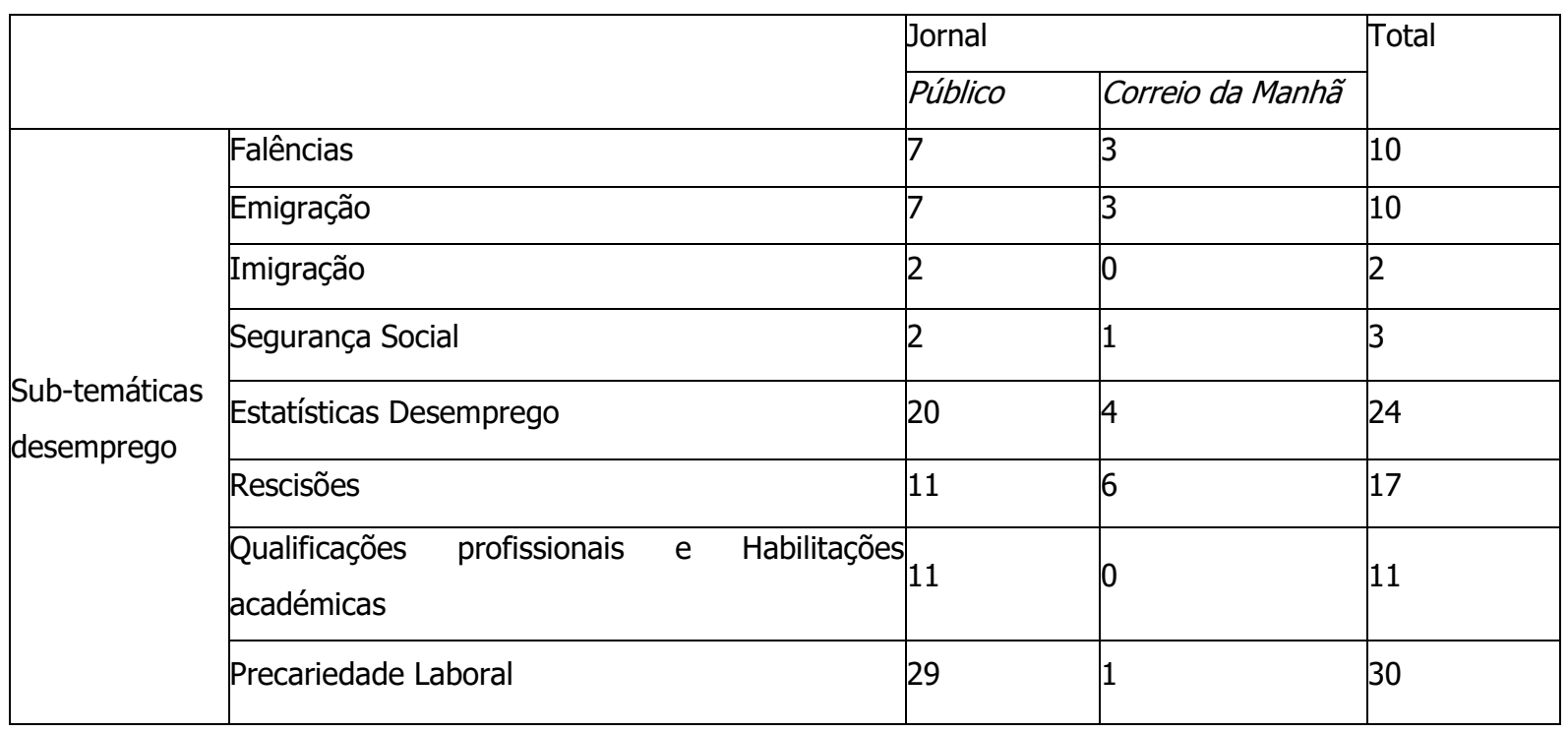




\begin{tabular}{|l|l|l|l|l|}
\hline Subsídio desemprego & 14 & 3 & 17 \\
\cline { 2 - 5 } & Código do trabalho e contratos & 9 & 0 & 9 \\
\cline { 2 - 5 } & Euestões Geracionais & 6 & 5 & 11 \\
\hline Economia & 14 & 9 & 23 \\
\hline Salário Mínimo & 5 & 0 & 5 & 2 \\
\cline { 2 - 5 } & Greves e Sindicatos & 1 & 1 & 15 \\
\cline { 2 - 5 } & Baixa Médica & 15 & 0 & 1 \\
\cline { 2 - 5 } & Outros & 0 & 1 & 4 \\
\cline { 2 - 5 } & Totais & 3 & 1 & 194 \\
\hline
\end{tabular}

Fonte: Elaboração própria

Numa categorização que atendeu a uma etiquetagem única por peça, em que o critério assumido era o identificar o argumento central da informação, podemos verificar logo à partida a diferença de amplitudes temáticas entre os dois jornais. Contudo, olhando para as frequências mais determinantes, percebemos de forma declarada no Público (e de forma indirecta no Correio da Manhã), como as notícias de desemprego estão ancoradas aos relatórios do Instituto Nacional de Estatística (INE), do Instituto do Emprego e Formação Profissional (IEFP) ou de entidades estrangeiras como o EUROSTAT. O que determina um número elevado de notícias no Público acerca de "estatística do desemprego", e por sua vez, um considerável número de notícias "económicas" no Correio da Manhã, que se produzem depois das periódicas actualizações das estatísticas do desemprego.

O discurso mediático do desemprego destes dois jornais é fortemente dependente das fontes oficiais. $O$ tratamento informativo é condicionado por este facto, optando por uma tónica eminentemente descritiva, mais enunciadora que propriamente interrogante para as causas dos números evidenciados. Contudo é importante referir que o tratamento dado pelo Público propõe abordagens histórico/comparativas que permitem uma melhor contextualização;

"Desemprego registado em Julho atinge novo pico dos últimos 30 anos" (Público, Agosto 2009)

Não será de estranhar que olhando para os dados, constatamos que só no jornal Público existam peças na secção internacional acerca do desemprego. Este facto indicia uma abordagem relacional, tomando em linha de conta a complexidade interdependente do fenómeno;

"Taxa de desemprego sobe para $13.2 \%$ e é a quinta pior da zona Euro" ( Público, Janeiro 2012)

Outro dado significativo, com uma diferença assinalável em termos de cobertura, é a contundência do tratamento do desemprego por parte do jornal Público. Alertando de forma mais evidente para a gravidade social do problema, assim como, para a expectativa negativa que se vai gerando na sociedade portuguesa. Evidência expressa no desencantado título de "um quarto dos portugueses teme perder em breve o emprego" (Outubro, 2009), ou na chamada de atenção para a transversalidade do fenómeno; "precariedade atinge um quinto da 
população activa" (Maio, 2009). E registando o tom crescente de conflictualidade social, mesmo que optando uma vez mais por privilegiar uma aproximação mais institucionalizada do problema, dando voz às acções de luta sindical.

Ao contrário do Correio da Manhã que constrói invisibilidade sobre a crispação social, paradigmática é ausência (em toda a nossa amostra) da cobertura em primeira página do dia do trabalhador (10 de Maio). Como hipótese forte, observamos uma tendência para a "despolitização" dos acontecimentos ideologicamente beligerantes com o statu quo social e político. Verificamos que o Correio da Manhã opta por uma abordagem "noticiosa" de natureza mais descritiva e de carácter mais neutro, ao invés do Público com uma aproximação jornalística mais densa, utilizando a entrevista e a reportagem de forma mais recorrente.

A Tabela 3 sublinha empiricamente o que acabámos de enunciar. Enquanto $50.6 \%$ do total de peças do jornal

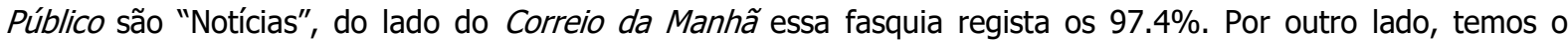
género "reportagem", mais complexo e que em termos informativos aprofunda e propõe uma dimensão mais compreensiva do assunto. Neste ponto em particular, temos um novo aprofundamento da tendência, já anteriormente identificada, dado que $35.3 \%$ dos trabalhos do Público sobre desemprego recorrem à reportagem, em claro antagonismo com o Correio da Manhã (como demonstra a tabela abaixo).

Figura 3 - Distribuição dos dados por Género informativo no Público e no Correio da Manhã

\begin{tabular}{|c|c|c|c|c|c|}
\hline & & & \multicolumn{2}{|l|}{ Jornal } & \multirow[t]{2}{*}{ Total } \\
\hline & & & Público & Correio da Manhã & \\
\hline \multirow{12}{*}{ Género informativo } & & Contagem & 79 & 37 & 116 \\
\hline & Notícias & \% Jornal & $50,6 \%$ & $97,4 \%$ & $59,8 \%$ \\
\hline & & $\%$ Total & $40,7 \%$ & $19,1 \%$ & $59,8 \%$ \\
\hline & & Contagem & 15 & 0 & 15 \\
\hline & Breves & \% Jornal & $9,6 \%$ & $0,0 \%$ & $7,7 \%$ \\
\hline & & $\%$ Total & $7,7 \%$ & $0,0 \%$ & $7,7 \%$ \\
\hline & & Contagem & 7 & 0 & 7 \\
\hline & Entrevistas & \% Jornal & $4,5 \%$ & $0,0 \%$ & $3,6 \%$ \\
\hline & & $\%$ Total & $3,6 \%$ & $0,0 \%$ & $3,6 \%$ \\
\hline & & Contagem & 55 & 1 & 56 \\
\hline & Reportagens & \% Jornal & $35,3 \%$ & $2,6 \%$ & $28,9 \%$ \\
\hline & & $\%$ Total & $28,4 \%$ & $0,5 \%$ & $28,9 \%$ \\
\hline \multirow{3}{*}{ Total } & & Contagem & 156 & 38 & 194 \\
\hline & & \% Jornal & $100,0 \%$ & $100,0 \%$ & $100,0 \%$ \\
\hline & & $\%$ Total & $80,4 \%$ & $19,6 \%$ & $100,0 \%$ \\
\hline
\end{tabular}

Fonte: Elaboração Própria

Vimos até aqui que há substanciais diferenças entre as duas publicações em análise, resultado fundamentalmente do tratamento jornalístico e dos diferentes objetivos que presidem à realização de ambas as publicações. Todavia, o foco desta pesquisa passa, em parte pela observação do fenómeno do desemprego jovem à lupa jornalística, é nesta linha de raciocínio que procurámos aferir, que discurso mediático é produzido. 


\section{Notas de fecho; o apagamento mediático do jovem desempregado}

O desemprego juvenil é um assunto de enorme transcendência social, já que as respectivas taxas de desemprego são invariavelmente mais altas que nos restantes grupos etários. Como dado relevante registe-se que o percentual de desempregados com idade inferior a 25 anos quadruplicou em relação aos valores de 2000, passando de $8,3 \%$ para um 37,7\% em 2012 ${ }^{8}$. De tal forma que a Organização Internacional do Trabalho (2012: 5), num documento dedicado em exclusivo à temática do desemprego juvenil, alertou para a gravidade do fenómeno, pois "o desemprego jovem atingiu proporções alarmantes". Mediante este cenário, queríamos perceber com especial interesse, como a imprensa postulava uma cobertura informativa para a complexidade do fenómeno em questão. Interessava perceber se se reproduzia essa importante conclusão que "o acesso activo (como protagonistas) e passivo (como referências) dos jovens ao discurso jornalístico é limitado" (Coelho, 2009: 375).

Figura 4 - Actores Discursivos nas peças dos jornais Público e Correio da Manhã

\begin{tabular}{|c|c|c|c|c|c|}
\hline & & & \multicolumn{2}{|l|}{ Jornal } & \multirow[t]{2}{*}{ Total } \\
\hline & & & Público & Correio da Manhã & \\
\hline & & Contagem & 12 & 2 & 14 \\
\hline & Jovem & \% Jornal & $7,7 \%$ & $5,3 \%$ & $7,2 \%$ \\
\hline & & $\%$ Total & $6,2 \%$ & $1,0 \%$ & $7,2 \%$ \\
\hline & & Contagem & 142 & 36 & 178 \\
\hline \multirow[t]{6}{*}{ Actores Discursivos } & Institucional & $\%$ Jornal & $91,0 \%$ & $94,7 \%$ & $91,8 \%$ \\
\hline & & $\%$ Total & $73,2 \%$ & $18,6 \%$ & $91,8 \%$ \\
\hline & & Contagem & 2 & 0 & 2 \\
\hline & Outros & $\%$ Jornal & $1,3 \%$ & $0,0 \%$ & $1,0 \%$ \\
\hline & & $\%$ Total & $1,0 \%$ & $0,0 \%$ & $1,0 \%$ \\
\hline & & Contagem & 156 & 38 & 194 \\
\hline \multirow[t]{2}{*}{ Total } & & \% Jornal & $100,0 \%$ & $100,0 \%$ & $100,0 \%$ \\
\hline & & $\%$ Total & $80,4 \%$ & $19,6 \%$ & $100,0 \%$ \\
\hline
\end{tabular}

Fonte: Elaboração Própria

Os dados contidos na Tabela 4 aproximam-nos de uma possível resposta à constatação anterior. Os jornalistas como "comunidade interpretativa" constroem o sentido do mundo, logo da notícia, desde as suas idiossincrasias. A redacção estabelece uma praxis determinada no modo de operar do jornalista, desenvolvendo sistema de procedimentos típicos. O que ajuda a explicar em ambos os periódicos, uma abordagem da construção da notícia assente no oficialismo das fontes. As razões para um jornalismo "oficialista" radicam numa producção jornalística que opera em lógicas de rotina (em contra-relógio); o argumento institucional, que se sobrepõe aos discursos

\footnotetext{
8 Para informações mais detalhadas consultar:

http://www.pordata.pt/Portugal/Taxa+de+desemprego+total+e+por+grupo+etario+\%28percentagem\%29-553
} 
"desinstitucionalizados" dos desempregados, é validado socialmente como um discurso de autoridade que não carece de explicações adicionais. O enquadramento noticioso é agilizando de forma quase mecânica. Na nossa análise de conteúdo, observamos a relação estreita entre novas informações acerca do desemprego, na relação directa com os comunicados oficiais que actualizavam as respectivas taxas.

O descontinuar desta estratégia do Correio da Manhã apenas se verifica aquando da utilização do discurso directo da figura do especialista, que confere um sentido de autoridade e propõe um dado pluralismo. 0 economista afecto a Confederação Geral dos Trabalhadores Portugueses (CGTP), Eugénio Rosa, aparece repetidas vezes como interlocutor da compreensão do fenómeno e como elemento de humanização das frias estatísticas. Que poderíamos resumir no seguinte conjunto de afirmações;

- Jovens vão suportar mais precariedade devido a facilitação dos despedimentos (CM, 16/12/2010)

- Menos emprego gera risco de exclusão e aumento da miséria (CM, 02/01/2011)

- Situação vai piorar, pois não se contabiliza o emprego precário e os que não procuram emprego (CM, 17/11/2011)

- Empresas aproveitam a crise para baixar salários (CM, 18/05/2012)

É uma abordagem jornalística sustentada num sistema de porta-vozes, que privilegia os aspectos de natureza formal. A leitura jornalística, que pouco indaga as culturas juvenis, parece estar refém da forma como ela é já socialmente definida (Pais, 1990). Existe um reforço mediático de uma dada representação juvenil, que assenta numa ideia dominante de hedonismo, aliada à concepção do adulto como productor e jovem como consumidor. Tal percepção plasma uma ideia sobre os jovens de irresponsabilidade e despreocupação, em suma de risco (Filho e Lemos, 2008). Esta formatação identitária condiciona fortemente outra possibilidade discursiva diante do mundo adulto (Filho, 2006). Por isso a argumentaria estigmatizante do conceito de juventude parece ser suficiente para o entendimento desta categoria social, em que o jovem nada teria para acrescentar à tipologia enunciada. $\mathrm{O}$ que inviabiliza de certa forma um discurso juvenil que possa ter espaço para se assumir na primeira pessoa.

Os meios ao produzirem um discurso tautológico acerca dos jovens, não permitem que se postule no espaço público as complexidades da juventude. Trajectórias estas que assumem comportamentos intermitentes, fragmentados, incertos, não lineares e reversíveis - a juventude dos percursos yo-yo. Numa progressiva diversificação, marcada por períodos de semi-dependência familiar, aliados ao figurino do trabalhador estudante, do jovem desempregado ou do biscateiro (Vieira, 2006).

Decorrente de coberturas jornalísticas simplistas, as abordagens primam por escassas e estratificadas no que toca as questões laborais juvenis, já que os poucos jovens a quem os media reconhecem atributos de representação são os licenciados; "54600 doutores sofrem no desemprego" (CM, 13/07/2010). Ao dar voz aos jovens graduados, os jornalistas apenas procuram os discursos directos que validem as estatísticas. A informação ilustrativa, pela utilização recorrente de discursos fragmentados, faz primar o anedótico sobre a complexidade informativa (Carriço Reis, 2009).

Notamos de forma reiterada esta prática jornalística num conjunto de temáticas relacionadas com este grupo de jovens; percebemos um dado sentimento geral de frustração decorrente de um investimento na educação que não gera retorno laboral. Este sentimento de frustração é potenciado na edição do Correio da Manhã no dia 22/06/2011 na peça "mais 3 mil 'doutores' no desemprego" em que "jovens com formação superior têm estado a 
ser fortemente afectados pelo desemprego. Em Novembro, eram 51796 as pessoas com habilitação superior que não tinham trabalho" (pág. 26). Ouvimos então o Filipe, que com 27 anos vai voltar a viver com os pais. A Vânia, que com um mestrado vai procurar emprego em fábricas, cafés, restaurantes. Discursos atravessados pela "vontade de emigrar", que Sofia assume de forma directa. A emigração omnipresente que é tratada com lateralidade pelos jornais em causa. Um conjunto de depoimentos e temáticas, tratadas de forma avulsa, que não consubstanciam uma explicação estruturada de um fenómeno multi-causal, que produz múltiplos efeitos.

A excepção que constatamos, foi na abordagem a condição feminina no mercado de trabalho. Tal facto se deveu a um processo de auto-identificação de género por parte das jornalistas. Diana Ramos sublinha a situação de maior precariedade da condição feminina, mulheres mais penalizadas pelos salários mesmo entre licenciados, como refere nas edições do Correio da Manhã de 02/01/2011 e de 18/01/2011. De igual modo a jornalista Raquel Oliveira sublinha a debilidade da condição feminina no mercado de trabalho, dando destaque em caixa a como o desemprego atinge com maior severidade as mulheres (CM, 30/04/2011).

Face ao exposto e na sequência da pergunta de partida e dos objectivos inicialmente traçados verificamos; pese a constatarmos estilos jornalísticos diferenciados no que tange a cobertura do desemprego juvenil por parte do Público e do Correio da Manhã, existe uma natureza substantiva da cobertura jornalística que atenua em dois aspectos essas diferenças estilísticas (que como vimos, muito se fizeram notar na abordagem geral a questão do desemprego). Um primeiro aspecto, foi verificamos um padrão de cobertura mediática em ambos os jornais. Público e Correio da Manhã primam por uma cobertura oficialista e simplista; assistimos a uma leitura institucionalizada, que privilegia as fontes oficiais em detrimento dos testemunhos juvenis. Notamos uma abordagem centrada nas dimensões estatísticas do problema, descaracterizando a compreensão acerca da complexidade do fenómeno e obviando a multiplicidade de temáticas que acarreta a questão do desemprego juvenil (que detalhamos na primeira epígrafe deste texto). Diante de enquadramentos tão minimalistas, os jornais não produziram o entendimento reflexivo que caracteriza este meio de comunicação.

Num segundo aspecto, registamos um interesse residual pela temática. Se atendermos que no período de 2009/2013 verificamos um total de 3642 edições (Correio da Manhã e Público), é lícito constactar que 194 peças encontradas sobre o desígnio da categoria desemprego são manifestamente residuais. Se levarmos em linha de conta que a temática do desemprego é uma das preocupações prementes da sociedade portuguesa, como evidenciam os estudos de opinião de que falávamos no início do texto, assistimos claramente a um descompasso entre a opinião pública e a opinião publicada.

Se colocarmos o foco no desemprego juvenil, com um total de 26 peças, ainda se intensifica de forma mais expressiva um alheamento da cobertura mediática em relação ao fenómeno. Dado que o tema não mereceu cobertura de maior por parte dos dois periódicos, a explicação parece radicar na forma de organização do negócio da imprensa. O modelo jornalístico vigente, orientado para a rentabilidade, pugna por adequar temáticas e mensagens aos públicos-alvo que cirurgicamente têm radiografados. O desinteresse juvenil pelos títulos generalistas parece ditar por parte das redaç̧ões dos jornais uma menorização das temáticas associadas a esta faixa etária. Já que segundo o anuário de comunicação da Obercom (2012), o leitor juvenil tem uma propensão maior para o consumo de jornais desportivos e de revistas de recorte geracional (com tiragens semanais e mensais).

A segmentação da imprensa tem como lógica associada a teoria do espelho e reforço, representa o tecido social que se reconhece a si mesmo na cobertura informativa (gerando empatia mediática) e acentua os rasgos dominantes, normas e valores, das identidades compradoras. Assim, as representações sociais das empresas mediáticas obedecem ao critério das "identidades lucrativas" (Sampedro, 2004). Constroem iminentemente discurso sobre os grupos, movimentos, agentes sociais que na troca de reforço simbólico retribuam com 
consumo fidelizado. Em parte isso explica o desinteresse pela cobertura da temática do desemprego, já que os desempregados se constituem como identidade não lucrativa. Assim como os jovens desde o seu peso demográfico residual, de $11,1 \%{ }^{9}$ em relação a população residente, são tomados como "lucro marginal".

Outro factor determinante radica no perfil do usuário juvenil, que responde a padrões de literacia mediática digital. Ora esta questão, é tão ou mais determinante, que a questão dos recursos económicos disponíveis, pois o processo de socialização mediático parece deslocar a modalidade de consumo tradicional para formas digitais de acesso a informação. O que coloca novos desafios às organizações mediáticas, no sentido da fidelização de uma geração de abundância informativa em regime de gratuitidade, que busca outros fóruns onde possa apropriar-se das mensagens de auto-representação e participe no definir da sua própria identidade (González, 2008).

\section{Referências bibliográficas}

Agee, W. e Traquina, N. (1984). O Quarto Poder Frustrado: Os Meio de Comunicação Social no Portugal PósRevolucionário. Lisboa, Edições Veja.

Alves, N.; Cantante, F.; Baptista, I. e Carmo, R. (2011). Jovens em Transições Precárias: Trabalho, quotidiano e futuro. Lisboa: Mundos Sociais.

Alves, P.; Poças, L. e Tomé, R. (2013). A crise do emprego jovem em Portugal e a negociação colectiva. Universidade da Beira Interior. Anais do XV Encontro Nacional de Sociologia Industrial, das Organizações e do Trabalho. Relações Sociais em Tempo de Crise: Trabalho, Emprego e Justiça Social. Covilhã.

Amaral, L. (2010). Economia Portuguesa. As Últimas Décadas. Lisboa: Fundação Francisco Manuel dos Santos/Relógio d'Água.

Bell, D. (1999). The Coming of Post-Industrial Society. New York: Basic Books.

Berlingieri, F.; Bonin, H. e Sprietsma, M. (2014). Youth Unemployment in Europe - Appraisal and Policy Options. (Relatório de estudo). Mannheim: Robert Bosch Stiftung.

Cardoso, G. (2007). A mídia na sociedade em rede. Rio de Janeiro: Editora FGV.

Carriço Reis, B. (2009). De la dictadura a la democracia; recuerdos y olvidos de la transición política española. Medios de comunicación y reconstrucción de la(s) memoria(s) colectiva(s) en España. Dissertação de doutoramento não publicada, doutoramento em Ciências da Comunicação, Universidad Rey Juan Carlos de Madrid. Madrid.

Coelho, M. (2009). Jovens no discurso da imprensa portuguesa: um estudo exploratório. Análise Social, XLIV (191), pp. 361-377.

COMISSÃO EUROPEIA (2012). Combater o desemprego juvenil: utilizar os fundos estruturais da UE para ajudar os jovens. Disponível em http://ec.europa.eu/commission 20102014/president/pdf/council dinner/youth action team pt.pdf (acedido a 15 de Agosto de 2013).

COSEC (2013). Estudo anual COSEC Insolvências 2012. Lisboa: COSEC. Disponível em http://www.aip.pt/irj/go/km/docs/sitemanager/www aip pt/documentos/homepage/informacao/201302 COSECInsolvencias12\%20\%284\%29.pdf (acedido a 1 de Agosto de 2013).

\footnotetext{
${ }^{9}$ Segundo os Censos de 2011.
} 
EUROFOUND (2014). Mapping youth transitions in Europe. Luxemburgo: Publications Office of the European Union.

Figueiredo, A.; Silva, C. e Ferreira, V. (1999). Jovens em Portugal. Análise longitudinal de fontes estatísticas. Oeiras, Celta.

Filho, J. e Lemos, J. (2008). Imperativos da conduta juvenil no século XXI: a 'Geração Digital' na mídia impressa brasileira. Revista Comunicação, Mídia e Consumo, 5 (13), pp. 11-25.

Filho, J. (2006). Formas e normas da adolescência e da juventude na mídia. Em J. Filho e P. Vaz (Orgs). Construções do tempo e do outro: representações e discursos midiáticos sobre alteridade (pp. 37-63). Rio de Janeiro: Mauad X.

Fragoso, A. (2010). Formas e expressões da comunicação visual em Portugal, contributo para o estudo da cultura visual do século $X X$, através das publicações periódicas. Dissertação de doutoramento não publicada, doutoramento em Design, Universidade Técnica de Lisboa. Lisboa.

Galtung, J. e Ruge, M. (1981). Structuring and selecting news. Em S. Cohen e J. Young (Eds.). The manufacture of news (pp.62-72). Londres: Sage.

Gans, H. (1979). Deciding what's news. Nova Iorque, Pantheon books.

Gonçalves, C. (2005). Evoluções recentes do desemprego em Portugal, Sociologia, 15, pp. 125-163.

González, G. (2008). El consumo juvenil en la sociedad mediatica. Comunicação, mídia e consumo, 5 (12), pp. 57-75.

Hughes, D. e Borbély-Pecze, T. (2014). Desemprego Jovem: Uma Crise Instalada - O papel das políticas de orientação ao longo da vida na resposta à oferta e procura de trabalho. (Concept Note No. 2). Lisboa: ELGPN.

INSTITUTO NACIONAL DE ESTATÍSTICA, [INE], (2014). Dia Internacional da Juventude. Lisboa: Destaque INE.

Lima, H., \& Reis, A. (2014). A hierarquização de notícias e os comentários do público nos sites de quatro diários portugueses. Escola Superior de Comunicação Social. Actas do $8^{\circ}$ Congresso SOPCOM: Comunicação Global, Cultura e Tecnologia. Lisboa.

Lopes, S. (2013). O desemprego de indivíduos com formação superior: a emigração como uma possível solução. Dissertação de mestrado não publicada, mestrado em Economia e Administração de Empresas, Universidade do Porto. Porto.

Marktest (2012). Anuário de Media \& Publicidade 2011. Lisboa, Grupo Marktest.

Marktest (2016). Anuário de Media \& Publicidade 2015. Lisboa, Grupo Marktest.

Matos, J., Domingos, N. e Kumar, R. (2011). Precários em Portugal. Lisboa: Edições 70.

OBERCOM (2006). Dietas de media em Portugal. Televisão, imprensa, radio e internet. Disponível em http://www.obercom.pt/client/?newsId=30\&fileName=wr1.pdf (acedido a 15 de Agosto de 2013)

OBERCOM (2012). Anuário da comunicação 2011-2012. Disponível em http://www.obercom.pt/client/?newsId=28\&fileName=Anuario2012.pdf (acedido a 1 de Setembro de 2013)

Oliveira, L. e Carvalho, H. (2010). Regulação e Mercado de Trabalho. Lisboa: Edições Sílabo. 
ORGANIZAÇÃO INTERNACIONAL DO TRABALHO, [OIT], (2012). The youth employment crisis: Time for action. Geneva: Bureau.

Pais, J. (1990). A construção sociológica da juventude - alguns contributos. Análise Social, XXV (105-106), pp. $139-165$.

Pais, J. M. (1991). Emprego juvenil e mudança social: velhas teses, novos modos de vida, Análise Social, vol. XXVI, 114, pp. 945-987.

Pais, J. (2003). Culturas juvenis. Lisboa: INCM.

Pereira, J. P. (2013) Crónicas dos días do lixo. Lisboa: Temas \& Debates/Circulo de Leitores.

PORDATA (s/d). Taxa de Desemprego Total e por grupo etário em Portugal. Disponível em http://www.pordata.pt/Portugal/Taxa+de+desemprego+total+e+por+grupo+etario+\%28percentagem\%29-553 (acedido a 15 de Agosto de 2014).

PORDATA (s/d). População residente com 15 a 64 anos e 65 e mais anos: por nível de escolaridade completo mais elevado em Portugal. Disponível em http://www.pordata.pt/Portugal/Popula\%c3\%a7\%c3\%a3o+residente+com $+15+a+64+$ anos + e+65+e+mais + an os+por $+n \% c 3 \%$ advel+de+escolaridade+completo+mais+elevado-332 (acedido a 1 de Agosto de 2014).

Reig, R. (1998). Medios de comunicación y poder en España. Barcelona: Paidós.

Ribeiro, R.; Frade, C.; Coelho, L. e Ferreira-Valente, A. (2015). Crise Económica em Portugal: Alterações nas Práticas Quotidianas e nas Relações Familiares. Faculdade de Ciências Sociais e Humanas da Universidade Nova de Lisboa. Livro de Atas do 10. Congresso da Associação Internacional das Ciências Sociais e Humanas em Língua Portuguesa. Lisboa.

Rowland, J.; Ferreira, V.; Vieira, M. e Pappámikail, L. (2014). Nem em emprego, nem em educação ou formação: jovens NEEF em Portugal numa perspetiva comparada (POLICY BRIEF 2014). Lisboa: ICS/OPJ.

Sá, V. (2014). O Desemprego Jovem em Portugal. Dissertação de mestrado não publicada, mestrado em Economia, Universidade de Coimbra. Coimbra.

Sampedro, V. (2004). Identidades mediáticas e identificaciones mediatizadas. Visibilidad y reconocimiento identitario en los medios de comunicación. Revista CIDOB d'Afers Internacionals, 66-67, pp. 135-149.

Schlesinger, P. (1978). Putting "reality" together. Londres, Constable.

Sennett, R. (1998). The Corrosion of Character. The Personal Consequences of Work in the New Capitalism. New York: W. W. Norton \& Company.

Tuchman, G. (1978). Making News: A study in the construction of reality. Nova Iorque, Free Press.

Vieira, J. (2006). Emprego e desemprego. Em V. Ferreira (Coord.). A condição juvenil portuguesa na viragem do milénio. Um retrato longitudinal através de fontes estatísticas oficiais: 1990-2005 (pp.90-109). Lisboa: Instituto Português da Juventude.

Vilas, B. (2013). Políticas Públicas e Desemprego Jovem. Dissertação de mestrado não publicada, mestrado em Ciência Politica, Universidade da Beira Interior. Covilhã.

Wickert, L. (2006). Desemprego e Juventude: Jovens em Busca do Primeiro Emprego. Psicologia Ciência e Profissão, 26 (2), pp. 258-269 